\title{
L.
}

\section{Ueber die Gegenwart des Caseïns und die reränderlichen Mengen desselben in dem Blute des Menschen und der Thiere.}

\author{
Von \\ Natalis Guillot and Felix Leblanc.
}

(Compt. rend. XXXI. p. 585).

Vor einiger Zeit theilten wir die Resultate einer Untersuchung mit, nach welcher das Caseĩn in dem Blute der Stillenden vorkommt. Seitdem haben wir unsere Untersuchungen bedeutend erweitert und mehr als siebenzig Proben Blut des verschiedensten Ursprungs untersucht. Wir können jetzt Schlüsse aus unseren Untersuchungen ziehen, die in Bezug auf Physiologie, Pathologie und Zoonomie nicht ohne Interesse sein werden.

Diese Schlüsse sind folgende:

Das Vorkommen des in dem Blute des Mannes, des Weibes und der verșchiedenen Thiere aufgelösten Caseins ist normal. Von den Thieren führen wir an das Blut des Ochsen, der Kuh, des Ziegenbocks, der Ziege, des Widders, des Hammels, des Schöpses, des Schweines, des Hundes und des Schaf- und Kuhfoetus.

Die Mengen des Caseins varïren je nach den Thieren, dem Geschlecht und je nach den verschiedenen Bedingungen der Nahrung, des gesunden oder des krankhalten Zustandes.

Diese Variationen bewegen sich innerhalb Grenzen, welche bei Weitem grősser sind, als die der bei der Analyse des Blutes bestimmten constituirenden Bestandtheile dieser Flüssigkeit.

In der Zeit der Schwangerschaft, kurze Zeit vor dem Gebären und wăhrend des Săugens hatte die Menge des Caseïns ihr Maximum sowohl bei den Frauen als auch bei den Weibchen der verschiedenen Thiere erreicht.

Während des Lebens im Uterus scheint die Ernährung des Foetus mindestens zum Theil auf Kosten des in dem Mutterkuchen häufig vorkommenden Caseïns, das wir auch in dem 
Nabelstrang nachgewiesen baben, vor sich zu gehen. Dieses interessante Factum ist zuerst von $\mathrm{Stas}$, nach der Entdeckung des Caseĩns in der Allantois nachgewiesen worden.

In gewissen pathologischen Fällen vèrmindert sich die Menge des Caseins beträchtlich; dies ist selbst in dem Blute 'schwangerer oder stillender Frauen der Fall. Das Caseĩn kann dann selbst in so geringer Menge vorkommen, dass es durch Reagentien nicht mehr nachgewiesen wird.

Diese Thatsachen sind bei schwangeren oder kürzlich entbundenen, an Rose, Brustentzündungen, Kindbettfieber, Hautwassersucht u. s. w. leidenden Frauen nachgewiesen worden.

Es wäre interessant, diese Thatsachen mit der Abwesenheit der Milchabsonderung in Beziehung zu bringen.

Analoge krankhafte Zustănde erklären auch die Abwesenheit des Caseĩns in dem Blute todtgeborener Kinder, während das Blut von lebenden Neugeborenen (Kindern und Thieren) viel Caseĩn enthält.

$O b$ das Caseïn, das durch Reagentien nicht nachgewiesen werden kann, coagulirt oder mit den Blutkorperchen vereinigt ist, oder aus dem Organismus ausgeschieden worden ist, oder auch in eine isomere eiweissähnliche Verbindung übergegangen, ist eine Frage, die wir bis jetzt noch nicht defnitiv beantworten kōnnen.

Das Blut castrirter Thiere (Ochse; Hammel) enthält eine ziemlich bedeutende Menge Caseĩn. Versuche in der Absicht angestellt, zu erforschen, ob dies auch bei nicht castrirten Thieren der Fall ist, zeigten uns, dass das Blut des Stiers und des Widders Casein in nicht unbeträchtlicher Menge enthält; bei dem Blute des Stiers bemerkten wir aber bei verschiedenen Individuen verschiedenen Caseingehalt.

Das Blut eines Ebers gab uns kein Caseĩn, wăhrend das einer Sau kleine Mengen lieferte.

Wir untersuchten ferner, ob der Zustand des Nüehternoder des Gesättigtseins einen Einfluss auf die in dem Blute enthaltene Menge Caseìn haben kơnnte. Die in dieser Richtung angestellten Versuche gaben uns durch ihre Variationen interessante Resultate; diese Untersuchungen sind aber noch nicht weit genug gediehen, um über diese Frage auf absolute Weise entscheiden zu kőnnen. Dasselbe gilt von dem Einllusse der Nahrungs- 
mittel auf die Gegenwart und die Menge des in dem Blute entbaltenen Caseĩns.

'Bildet nun das Casein ein Nahrungsmittel, das weit geeigneter zur Assimilation ist, als die andern eiweissartigen Substanzen? Wohl möchte man versucht sein, dies anzunehmen, wenn man die letzterwähnten Thatsachen mit den Ernährungserscheinungen bei dem Foetus auf Kosten eines an Casein reichen Blutes vèrgleicht.

Es steht fest, dàss in dem Blute săugender gesunder Weibchen das. Caseïn sich in der grōssten Menge findet, und dass das unter diesen Umständen aufgefangene Blut sich vollkommen zur Darstellung des Caseîns ejgnet. Die Methoden der Ausziehung und der Reinigung sind mindestens eben so einfach, als ob es sich um die Darstellung des Caseìns aus der Milch handelte. Die Gegenwart des Caseins in bedeutender Quantităt in der Milch der Milchkühe veranlasste uns Zucker in demselben Blute zu suchen.

Bis jetzt haben wir keine bedeutenden Mengen Blut zur Untersuchung verwendet, aber bei Anwendung eines Liters Blut wurden durch die Trommer'sche Probe kleine Mengen von Zucker durch die Bildung eines gelben Kupferoxydulhydratniederschlags angedeutet. Es ist zu bemerken, dass die in Alkobol löslichen Substanzen in der Kupferoxydlösung keinen Niederschlag hervorbrachten, wăhrend die Reduction unter dem Einflusse des mit Alkohol behandelten Rückstandes der wãssrigen Lǒsung eintrat. Dieser Versuch deutet daher mehr auf die Gegenwart des Milclauckers als auf die des Krümelzuckers. Nur, wenn man grŏssere Mengen Blut von Milchkühen verwendet, wird es möglich sein, in dieser Beziehung zu einem sicheren 